\title{
Antecedent of Job Stress: Causes Need to be Identified A Case of Secondary School Teachers
}

\author{
SHAHZAD KHAN \\ Assistant Professor University of Haripur Pakistan \\ shahzadkhan@uoh.edu.pk \\ Dr. MUHAMMAD TARIQ KHAN \\ Assistant Professor University of Haripur Pakistan \\ Dr.tariqkhanzada@yahoo.com \\ MUHAMMAD ATIQ RAFIQUE KHATTAK \\ Lecturer University of Haripur Pakistan \\ atiqkhatttak@hotmail.com
}

\begin{abstract}
The purpose of the study is to identify the possible antecedents of stress in secondary schools teaches. Many factors are there which lead stress specifically in private sectors. However it's important to find the essential role playing factor of stress in private schools teachers. The research identified the antecedents of job stress in private schools teachers in Peshawar Pakistan. Population of the study has been chosen on convenience sampling a non-probability technique. A 5 point lickert Scale structured questionnaire was distributed among 100 schools teachers. The data collected through questionnaires was analyzed and interpreted using ANOVA, and Regression co-efficient. The findings of the study revealed that co-worker relation and school discipline are the key factors of schools teachers stress.
\end{abstract}

Keywords: Job Stress, Private Schools, Regression, discipline, Factors.

\section{Introduction}

The stress in our life is always present because of our nature, attitude and expectations. Some of the people can able to avoid it but some take high stress due to their competitive job environment. People are usually more worry about the outcomes of jobs. Because of this stress people can't spend their time in organizationhaply and because of this factor they can't satisfied and therefore they always feel frustrated when they communicate with their colleagues. Therefore it is essential to highlight the determinant of job stress. The aim of this research is to identify the stressors issues that influence their mental and physical health. This research is about to investigate the relationship of stress on secondary school teacher and their job satisfaction. This research is examined the determinant of workplace stress under the study of management. This will also show the positive and negative relationship between job satisfaction and job stress. The area of research is government school in Haripur division. 


\section{Literature Review}

\subsection{Stress}

Stress is a condition of mind where tension is constantly or with regular interval causing worry and problems in both personal and professional life. Generally stress is affecting our body both mentally and physically. The study of Abraham (2000) shows that stress develop as a return of some real life experiences and activities. Stress affects the job related activities of the employees and it affects productivity directly. Bacon (1996) describe in his study that stress appear with regular interval but its consequences are regular on employees performances. The work of Barley Knight (1992) describe that stress is developed from many reasons and its antecedents depends from person to person and culture to culture and from environment to environment. Identifying stress in employees is one of the important reason for better productivity. Employees with stressscan not perform their best. Creativity and innovation are only produced by the workers who are stress free Brent (2006).

\subsection{Antecedents of Stress in Schools Teachers \\ 2.2.1 Co-Worker Relationship}

On work place the relations with other colleagues play an important role in organizational development Spiers (2003). The place where employees are not feeling comfortable with each other they cannot produce their best. According to Cooper (2011) social relations at workplace play an important role in individual performance. A place where employees are not well oriented are under stress. He describe the study of employees where no social interaction between coworkers are under stress until they do not understand each other. In one of his case he mentioned employees resign due to non-comfortably issues with colleagues. Marshall (1976) mentioned in his study that boss and subordinates are under contact stress if they are unable to work together. Half of the human life is spend at workplace the same stress of job is then being carried with that person personal life. In study of Cooper (2001) shows that demographic and cultural variations lead personnel differences which further leads to stress at work.

\subsubsection{Remuneration}

In now a day competitive world employees need to be retained. Griffiths (1995) study shows that good compensation is one of the factor for good productivity of the employees. A lesser financial compensation is one of the major factor of employees stress which lead to less productivity. Before hiring its important to now the needs of the employees with the need of organization. According to Coyle (2005) similarly in the case of teachers also need good compensation for better teaching and creating goof learning environment. Stress and salary are directly connected as a good salary will motivate and a less salary will leads toward stress and then leads towards less productivity. Finding a good compensation plan for your employees is one of the best innovations in human resource planning. The HR team need to find and evaluate a best compensation deal for their employees in order to avoid stress and productive contribution to organization.

\subsubsection{Workload}

Martha et al (2000) shows that workload is the number of assignment which are assigned to an employee during working hours. Fahy(2007) shows that defining job descriptions 
clearly reduce the stress of employees. While not clear descriptions are one of the factor of stress. Gustavsen (1980) shows in his study that on job duties are the requirements of a job however exceeding it from limit like overtime or exceeded work leads to employee stress. Private sectors employees are under the contact stress as per the study of Guldenmund(2000) the work load is high in private firms in comparison of public sector. Johnson (1985) shows in his study that teachers with extra courses become under stress in case of university of berlin. A report issued by Health and Safety Commission (HSC) (1992) shows that less workload to employees leads to a pleasant balance life.

\subsubsection{Physical Stress}

According to the stud of Heany(1995) physical stress is and mental stress are directly connect to each other. Employees work under the situation where they are also under the physical stress can lead to a more severe stress condition and even faster. The study of Hsu (2008) indicates that few jobs are such in nature which are inter connected like teaching where students and teachers are interconnected with each other. In such circumstances the stress flew from one side to another side.This study tested the hypothesis that teachers who participate in aerobic exercise and have increased parent involvement in their classrooms will have lower stress and consequently are significantly less likely to experience burnout and job dissatisfaction.ILO (2008) shows that the additional assignment in a class room lead to physical stresss for both teachers and students.

\subsubsection{Promotion}

Smith \& Segal (2007) describe in their study that some of the peoples are only doing their job for authority not for need base. They only do well for sake of promotion. A promotion is not only a way to add more responsibilities to an employee but is a major form of boosting employee motivation and moraleStranks (2005). This results in high performance in field of teaching.

\subsubsection{Government Policies}

Kagan (1995) say that an education policy is a past or up to date statement which explain recommended or exclude a course of action to run the system of education. A teacher policy is guided by a vision and essential character that defined policies.Many of the government policies are not good for teachers i.e. recently government announced the NTS test that is essential for all teachers that create the panic condition, similarly this government policy increase the level of stress that cause hurdle in way of educationKao (2007).

\subsubsection{Communication Gap}

Karasek(1990) communication between teacher and student has the potential to improve the learning experience and create a positive environment in the class room. How-ever the relationship take works in both ends. The example of this problem is if the teacher is Pashto speaker and students are local, because of this problem they can't understand the class lecture.Lazarus (1985) shows that due to the communication gap teachers and student have misunderstanding and this lead to the cause of stress for both parties. Much time fail to create engaging lessons and struggle to connect their students on one-to-one basis. Students also have unaddressed language or speech difficulties which lead to poor communicationWilliams(1998). 


\subsection{Theoretical Framework of the Study}

Schools teachers is greatly influenced by different antecedents. The figure below shows the relationship between stress with many factors. In this study stress is depending upon eight independent factors which are promotion, workload, physical stress government policies, remunerations, school discipline, communication gap, and coworker relations. But here its important to find which factor is playing the key role in schools teaches stress.

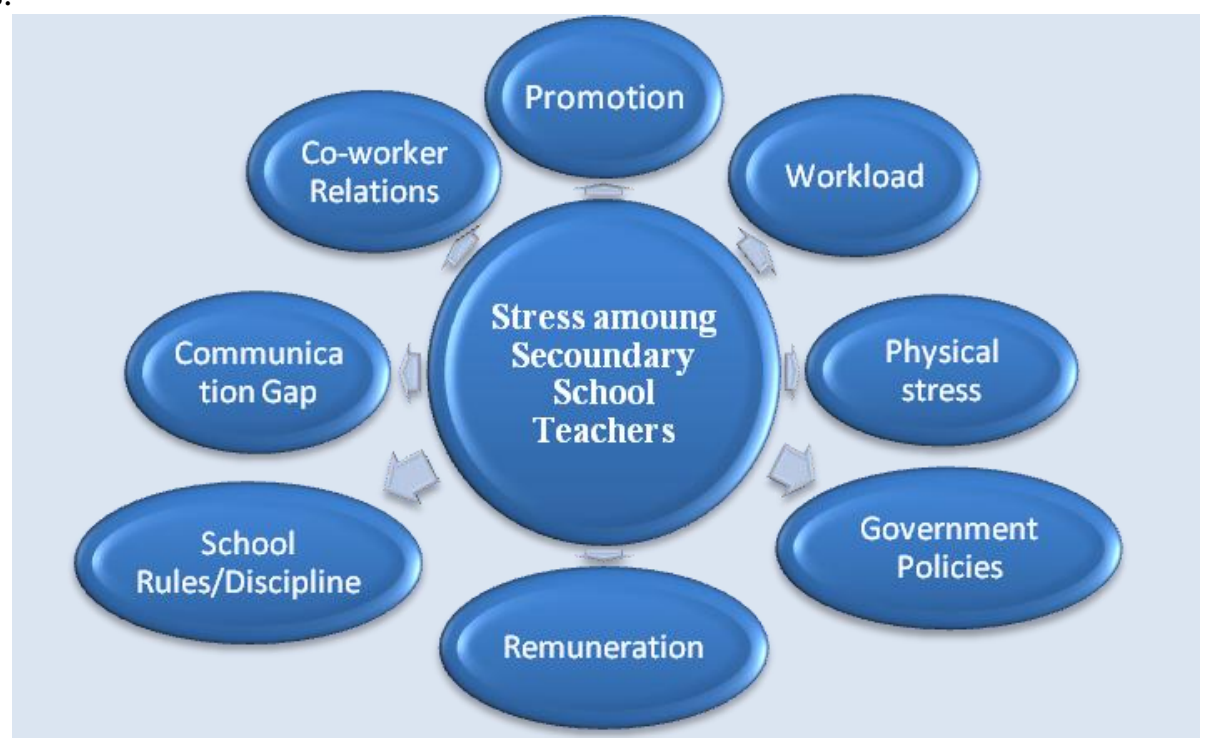

Figure 1: Study theoretical Framework

\subsection{ResearchHypothesis}

This study carries eight independent variables. These eight independent variables has a relationship with schools teachers stress. The study is based on following hypothesis:

H1: Workload has positive impact on school teachers stress.

H2: Physical stress is positively related to school teachers stress.

H3: Government policies have positive impact on school teachers stress.

H4: Remuneration has positive relationship on school teachers stress.

H5: School discipline has a great influence on school teachers stress.

H6: There is positive relationship between communication gap and school teachers stress.

H7: Co-workers relationship has positive impact on school teachers stress.

H8: Promotion is positively related to school teachers stress.

\section{Methodology of the Study}

\subsection{Sample size}


The Population of the study was the private schools of Peshawar Pakistan. For the purpose on convenient basis, Peshawar Model School, UPS, Forward Model Schools and Beacon house Schools System were selected as a non-probability sampling. The population was the teachers of the above mentioned schools and on conveniences basis a sample of 110 has been chosen consists of all teachers in private sector schools. For the final analysis 100questionnaire has been used. The 3 questionnaire were not received while 7 were incomplete so not considered for final analysis.

\subsection{Questionnaire}

In this study questionnaires were used as a research instrument. Questionnaire contained closed ended, and likert scale questions. Questionnaires were personally administered among 70 teachers of private schools in Peshawar city (Peshawar model school, Forward public school, UPS, and The Beacon House Schools system).

\section{Result and Analyses}

\subsection{Socio-Demographic Profile}

Below table 1 represent the demographic analysis of 100 respondents. The description of the table table below shows that male respondent is $74 \%$ while there are $26 \%$ female respondents. Below table also represents that only $9 \%$ are in the age group of 20-25, while $21 \%$ respondents are in age of 26-30. In age range of 31-35 there are $26 \%$ respondents. While $44 \%$ of the respondents of the study are above age of 36 . The demographic of the study shows that only $17 \%$ of the respondents are in between income range of 10000-20000. There are 47\% respondents who are in income range of 20000 to 30000 .

Table 1: Demographical Result

\begin{tabular}{cccc}
\hline Measures & Items & Frequency & Percentage \\
\hline Gender & Male & 74 & $74 \%$ \\
& Female & 26 & $26 \%$ \\
Age & $20-25$ & 9 & $9 \%$ \\
& $26-30$ & 21 & $21 \%$ \\
Family Income & $31-35$ & 26 & $26 \%$ \\
& $\geq 36$ & 44 & $44 \%$ \\
& $>20000<<30000$ & 17 & $17 \%$ \\
& $>30000<40000$ & 47 & $47 \%$ \\
& $>40000<50000$ & 25 & $25 \%$ \\
& $>50000$ & 7 & $7 \%$ \\
& & 4 & $4 \%$ \\
\hline
\end{tabular}

In the respondents $25 \%$ are in range of 30000 to 40000 while only $7 \%$ respondent is having monthly income between 40000 to 50000. The respondents who has more than 50000 incomes per month they are only $4 \%$ in the study.

\subsection{Reliability of Scale}

Below table 2 shows the Cronbach's Alpha of the variables. The reliability of the data has been made on the basis 100 respondent response.

Table 1: Reliability of the Scale of the study 


\begin{tabular}{ccc}
\hline S.No & Variables & Cronbach's Alpha \\
\hline 1 & Job stress & 0.901 \\
2 & Promotion & 0.892 \\
3 & Workload & 0.803 \\
4 & Physical stress & 0.722 \\
5 & Government Policies & 0.719 \\
6 & Remunerations & 0.883 \\
7 & School Discipline & 0.898 \\
8 & Communication Gap & 0.892 \\
9 & Coworker Relations & 0.734 \\
\hline
\end{tabular}

The above table shows that reliability of the data collected from respondents. The table represent a reliable response from the respondent because the variables are exceeding from $70 \%$ which is the standard of acceptance for reliability.

The below table calculations suggest that the responses given by respondents of the study are reliable.

The following results are obtained from the multiple linear regressions.

Table 3: Multiple Regression Results for Variables of the study

\begin{tabular}{ccccc}
\hline Model & $\mathrm{R}$ & R Square & Adjusted R Square & $\begin{array}{c}\text { Std. Error of the } \\
\text { Estimate }\end{array}$ \\
\hline 1 & .883 & .779 & .676 & .3125 \\
\hline
\end{tabular}

a. Predictors: (Constant), promotion, workload, physical stress government policies, remunerations, school discipline, communication gap, and coworker relations.

The above table 3 shows that the dependent variable, (Teacher stress) is affected by $67.6 \%$ by independent variables (promotion, workload, physical stress government policies, remunerations, school discipline, communication gap, and coworker relations). It shows that (promotion, workload, physical stress government policies, remunerations, school discipline, communication gap, and coworker relations) are responsible for school teachers stress. The over all model is also noteworthy, tested with the help of ANOVA. The results are given in the following table.

Table 4: ANOVA Results

\begin{tabular}{|c|c|c|c|c|c|c|}
\hline \multicolumn{2}{|c|}{ Model } & Sum of Squares & Df & Mean Square & $\mathbf{F}$ & Sig. \\
\hline \multirow[t]{3}{*}{1} & Regression & 5.671 & 11 & .652 & 2.416 & $.000^{\mathrm{a}}$ \\
\hline & Residual & 17.341 & 44 & .736 & & \\
\hline & Total & 17.498 & 55 & & & \\
\hline
\end{tabular}

a. Dependent Variable: School teacher stress

b. Predictors: (Constant), promotion, workload, physical stress government policies, remunerations, school discipline, communication gap, and coworker relations. 
Above table no 4 shows that the level of significance, it clearly describe that all the factors like promotion, workload, physical stress government policies, remunerations, school discipline, communication gap, and coworker relations are related to schools teachers stress and the relationship between them is significant as compared to alpha value $=0.05$ table 3 shows coefficient of all independent variables.

Table 5: Regression Co-efficient

\begin{tabular}{|c|c|c|c|c|c|c|}
\hline \multirow{2}{*}{\multicolumn{2}{|c|}{ Model }} & \multicolumn{2}{|c|}{$\begin{array}{l}\text { Coefficients } \\
\text { Unstandardized } \\
\text { Coefficients }\end{array}$} & \multirow{2}{*}{$\begin{array}{c}\text { Standardized } \\
\text { Coefficients } \\
\text { Beta }\end{array}$} & \multirow[b]{2}{*}{$\mathrm{t}$} & \multirow[b]{2}{*}{ Sig. } \\
\hline & & $\mathrm{B}$ & Std. Error & & & \\
\hline 1 & (Constant) & 4.241 & .869 & & 5.341 & .000 \\
\hline & Promotion & .126 & .141 & .117 & 2.173 & .000 \\
\hline & Workload & .311 & .121 & .218 & 1.918 & .000 \\
\hline & Physical stress & .107 & .149 & .101 & 1.469 & .000 \\
\hline & Government policies & .182 & .158 & .191 & 1.151 & .000 \\
\hline & Remunerations & .239 & .178 & .291 & 1.891 & .000 \\
\hline & school discipline/policies & .184 & .187 & .142 & 2.184 & .000 \\
\hline & communication gap & .116 & .134 & .136 & 2.090 & .000 \\
\hline & coworker relations & .259 & .193 & .297 & 1.861 & .000 \\
\hline & Overall & .067 & .301 & .061 & 0.347 & .000 \\
\hline a. De & endent Variable: School te & eer stre & & & & \\
\hline
\end{tabular}

Above table 5 shows that all factor have significant relationship with dependent variable stress. In the table, standardized coefficient shows that all the factors are definitely affecting the stress and is becoming one of the stress factor in school teacher. As the table clearly states, each and every factor is notably related to stress. Under the standardized coefficients it is evident that, coworker relationship is the one major important factor causing schools teachers stress in private educational institutes with a standardized coefficient 0.297 in order of significance. The second important factor is remunerations with a standardized coefficient 0.291 . The third important factor is workload with a standardized coefficient 0.218 . Hence there are three important factors which are responsible for employee stress such as coworkers relations, remunerations and workload. Other factors also influence stress such as school policies $(\beta=.142)$, communication gap $(\beta=.116)$, overall $(\beta=.067)$.

\section{Conclusion}

Stress of schools teachers is an important factor need to be understand. Teachers are the one who developed nations, under the contact stress it's not possible for them to produce their best services. In schools teachers these factors were promotion, workload, physical stress government policies, remunerations, school discipline, communication gap, and 
coworker relations and had a great effect on stress. It can be concluded that, there is a promotion, workload, physical stress government policies, remunerations, school discipline, communication gap, and coworker relations on teachers stress but coworker relations and remunerations and workload are the key factors for schools teachers in private schools of Peshawar city Pakistan.

\section{References}

Abraham, R., (2000). The role of job control as a moderator of emotional dissonance and emotional intelligence-outcome relationships.Journal of psychology [J Psychol], Vol. 134, (2), pp. 169-84

Bacon, J. (1996). The Health and Safety Implications of Changing Patterns of Employment, RoSPA Consultation Seminar on Health and Safety Implications of Changing Patterns of Employment, Charing Cross, London

arley, S. \& Knight, D., (1992).Toward a cultural theory of stress complaints se in Staw B and Cummings L (eds.), Research in Organizational Behaviour, JAI Press

Belchamber, B. (2006). Why colouring and what's the therapy? Retrieved September 2, 2013, from Colouring Therapy http://www.coloringtherapy.com/t_on_coloring_therapy.htm

Carole, S. (2003).Tolley's Managing Stress in the Workplace, Publisher Taylor \& Francis, 212-218

Cary, L. C. (2011). Occupational Health and Safety for Small and Medium Sized Enterprises, Publisher Edward Elgar Publishing, 89-94

Cooper, C. L. \& Marshall J.(1976). Occupational sources of stress: a review of the literature relating to coronary heart disease and mental ill health. $J$ Occup Health Psychol;49:11-28.

Cooper, C, (2001). The psychological implications of the disposable workforce: the future stressors ${ }^{\text {ee }}$ in Pearce J,Taking the stress out of work - Conference Synopsis ${ }^{\text {ee }}$, Stress News. Vol.13 No.4, 2001.

Cox, T., \& Griffiths, A. (1995). The nature and measurement of work stress: theory and practice. In: Wilson JR, Corlett EN, et al, eds. Evaluation of human work: a practical ergonomics methodology, 2nd ed. London: Taylor \& Francis:783-803.

Coyle, D. (2005). A systematic review of stress among mental health social workers. International Social Work, 48(2), 2001-211

Davis, M. (2000), The Relaxation \& Stress Reduction Workbook Oakland, CA: New Harbinger Publication, Inc.

Fahy, A. (2007). The unbearable fatigue of compassion: Notes from a substance abuse counsellor who dreams of working at Starbuck"es. Clinical Social Work Journal, 35(3), 199-205

Gardell, B. \& Gustavsen, B. (1980). Work environment research and social change: current developments in Scandinavia. J OccupBehav;1:3-17.

Gronningsaeter, H. (1992). Improved health and coping by physical exercise or cognitive behavioral stress management training in a work environment. Psychology and Health 7:147-63. 
Guldenmund, F. (2000). The nature of safety culture: a review of theory and research. 34: 215-257.

Hall, E. M. \&Johnson J. V. (1985). Depression in unemployed Swedish women.SocSci Med;27:1349-55.

Hall E. M. Women, work and health: employment as a risk factor for coronary heart disease. J PrevCardiol 1994;4:365-84.

Health and Safety Commission (HSC) (1992) the Health and Safety System in Great Britain, HMSO, London

Health and Safety Executive (2000).Organizational interventions for work stress: a risk management approach. Norwich: Her Majesty's Stationery Office.

Heany, C. A., Price, R. H. \& Refferty, J. (1995). Increasing coping resources at work: a field experiment to increase social support, improve work team functioning, and enhance employee mental health. J OrganisationalBehav; 16:335-52.

Hsu, S. (2008). A cross-cultural study of organizational factors on safety: Japanese vs. Taiwanese oil refinery plants. Accident Analysis and Prevention 40: 24-34

ILO, (2008). OSH Management System: A tool for continual Improvement. [Pdf], Available at: www.ilo.org/safeday [Accessed 23 August 2013].

Jaffe-Gill, E., Smith, M., Larson, H., \& Segal J. (2007). Understanding stress: Signs, symptoms, causes, and effects. [Online]. Retrieved from: http://www.helpguide.org/mental/stress_signs.htm on September 4, 2013

Jeremy, W. S. (2005). Stress At Work: Management and Prevention, Publisher Elsevier/Butterworth-Heinemann, 232

Johnson, J. V., Stewart, W., Friedlund, P., et al. (1996). Long-term psychosocial work environment and cardiovascular mortality among Swedish men. Am J Public Health $86,324-31$.

Kagan, N.I., Kagan, H., \& Watson, M. G. (1995). Stress reduction in the workplace: the effectiveness of psychoeducational programs. J CounsellingPsychol;42:71-8.

Kao, C. (2007). Analysis of safety culture and safety performance relationship of a major petrochemical corporation in Taiwan. International Symposium, pp 3-4. http://process-safety.tamu.edu

Karasek, R. A., \& Theorell, T. (1990). Healthy work: stress, productivity, and the reconstruction of working life. New York: Basic Books.

Lazarus, S. \& Folkman, S. (1998). Stress, appraisal and coping. New York: Springer, 1984.

Williams, S. Michie, S. \& Patani S. Improving the health of the NHS workforce. London: The Nuffield Trust. 


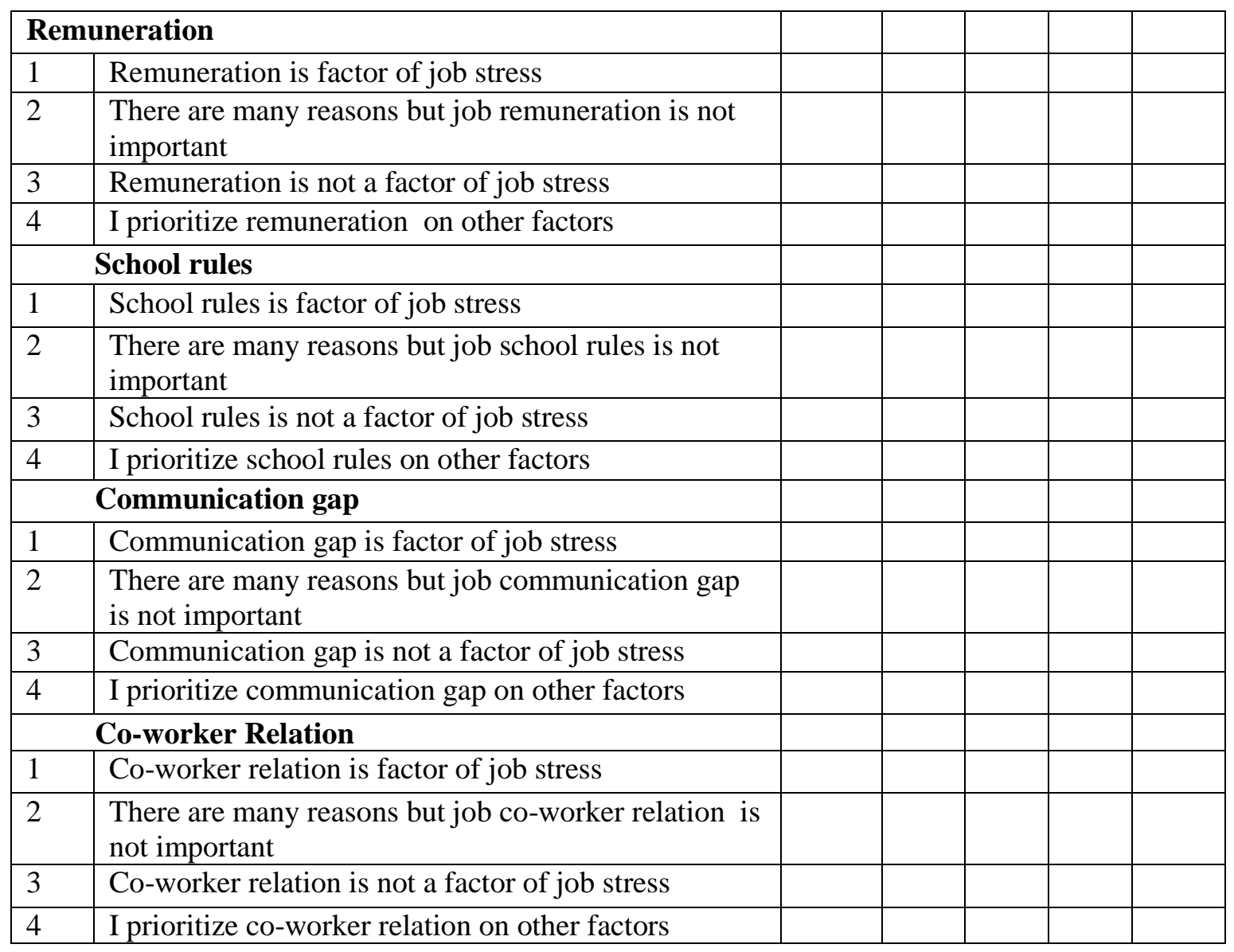

